\title{
The Relationships between Exchange Rates and Stock Prices: Empirical Investigation from Johannesburg Stock Exchange
}

\author{
Md. Mahmudul Alam \\ $\mathrm{PhD}$ Researcher \\ Institute for Environment and Development (LESTARI) \\ National University of Malaysia (UKM), Malaysia; \\ E-mail: $\underline{\text { rony000@gmail.com }}$
}

Md. Gazi Salah Uddin

Senior Lecturer

Department of Business Administration

East West University

Dhaka, Bangladesh

E-mail: rimsust2002@yahoo.com

\author{
Khan Md. Raziuddin Taufique \\ Assistant Professor \\ School of Business, Presidency University \\ Dhaka, Bangladesh \\ E-mail: kmrtaufiq@gmail.com
}

\section{Citation Reference:}

Alam, M.M., Uddin, M.G.S., and Taufique, R. 2011. The Relationships between Exchange Rates and Stock Prices: Empirical Investigation from Johannesburg Stock Exchange, Inventi Rapid: Emerging Economics, Vol. 2011(3), Available at < http://www.inventi.in/Rapid/EmergingEconomies/Abstract.aspx?ID=2354>. $\quad$ (ISSN 2231-2617; Publisher- Inventi Journals Pvt. Ltd)

This is a pre-publication copy.

The published article is copyrighted by the publisher of the journal. 


\title{
The Relationships between Exchange Rates and Stock Prices: Empirical Investigation from Johannesburg Stock Exchange
}

\author{
Md. Mahmudul Alam, Md. Gazi Salah Uddin, Khan Md. Raziuddin Taufique
}

\begin{abstract}
This study seeks evidence supporting the existence of market efficiency and exchange rate sensitivity on stock prices in the Johannesburg stock exchange (JSE). The sample includes the daily price indices of all securities listed on the JSE, and the exchange rate of the USD/Rand for the period since January 2000 to December 2004. The results from the unit root test, the ADF test and the causality test at the Granger sense provide evidence that the Johannesburg stock exchange (JSE) is informationally efficient. It has a long run comovement with exchange rate, and long run equilibrium or steady state. Hence, in JSE there is a strong possibility that foreign direct investors and forex market traders cannot influence and gain abnormal extra benefits by using exchange rate mechanism or by using exchange rate to forecast stock prices in the market. So, JSE is semi-strong form efficient. Through cointegration test, this paper gives more insight on the concept of market efficiency and the reliability of the results. These results are important to security analysts, investors, and security regulatory exchange bodies in policy making decision to improve the market conditions.
\end{abstract}

Key Words: Exchange Rate, Sock Prices and Granger Causality JEL Code: C22, G14

\section{INTRODUCTION}

The term efficiency is used to describe a market in which relevant information is impounded into the price of financial assets. Efficiency is the central concept of financial markets. Efficient Market Hypothesis (EMH) is an idea that market prices incorporate all information rationally and instantaneously. A mature and sizeable stock market is perceived across the globe as a barometer of the economic health and prospect of a country as well as a register of the confidence of domestic and global investors.

There are three forms of measuring the stock market efficiency- the weak form, the semi strong form and the strong form. The weak form of market efficiency uses information based on historical or past prices. This form claims that all past prices of a stock are reflected in today's stock price. Therefore, technical analysis cannot be used to beat the market. Theoretical in nature, weak form efficiency advocates assert that fundamental analysis can be used to identify stocks that are undervalued and overvalued, hence keen investors looking for profitable companies can earn profits by researching financial statements. In the weak form EMH past values of the index cannot be used to forecast the current values which can be tested by unit root test .i.e. if the index is $\mathrm{I}(1)$ it means that the market is efficient in the weak form. The semi-strong form makes use of past information as well as all publicly available information. This implies all public information is incorporated into the current price of a stock. This stage of EMH suggests that only information that is not publicly available can be used to make abnormal profits. The index can be forecasted even if public information is issued by using the test of Granger Causality. If there is causality then the market is not efficient in semi-strong form. The strong form holds if the market incorporates all information, both public and private (insider information). Therefore, any information known 
to the public or a private source should be fully reflected in the security's current price for the EMH to hold.

Classical economic theory suggests a relationship between the stock market performance and the exchange rate behaviour. Stock markets are potentially affected by interest rate and exchange rate changes but the degree of impacts vary widely. Reliable and realistic estimations of the sensitivity of stock returns to the changes in exchange rates is a crucial factor in exchange rate exposure management and government policy implementation towards financial markets in a country. This research is subject to the Johannesburg stock exchange in South African stock market to the test of efficiency of the market, and exchange rate sensitivity on stock prices.

\section{LITERATURE REVIEW}

Generally it is believed that the markets in the developing and less developed countries are not efficient at all. The findings from the empirical testing of the efficient market hypothesis (i.e., random walk) with stock prices have been mixed. Early studies by Fama ${ }^{[1]}$, Samuelson $^{[2]}$, and Working ${ }^{[3]}$ could not reject random walk theory for markets, but early rejection was found by Niederhoffer \& Osborne ${ }^{[4]}$. Few researchers argue that there is little theoretical basis for strong attachment to the null hypothesis that stock prices follow a random walk. ${ }^{[5]}$ Based on the sampling distributions of variance ratios over different sampling intervals, researchers also found that stock returns do not follow a random walk. ${ }^{[6]}$ On the other hand, Shiller ${ }^{[7]}$ indicated that there are reasons that the random-walk behaviour of stock prices should hold, and there is plenty of evidences suggesting that stock prices do follow a random walk. Harvey ${ }^{[8]}$ stated that stock returns of emerging countries are highly predictable and have low correlation with stock returns of developed countries. He concluded that emerging markets are less efficient than developed markets and that higher return and low risk can be obtained by incorporating emerging market stocks in investors' portfolios. Although some studies support Harvey ${ }^{[8]}$ statement about non randomness of emerging markets' stock prices ${ }^{[9-12]}$, some other studies related to these same markets do not ${ }^{[13,14]}$.

There are several studies that tested efficiency of Johannesburg Stock Exchange (JSE). The evidence on all three forms of market efficiency is quite mixed for the JSE. Gilbertson $^{[15]}$ found evidence supporting strong-form efficiency, where Knight and Firer ${ }^{[16]}$ rejected the strong-form efficiency. Again, Knight and Afflect-Graves ${ }^{[17]}$ rejected semi-strong form efficiency but Knight, Afflect-Graves and Hamman ${ }^{[18]}$ showed semi-strong form efficiency of JSE. Jammine and Hawkins ${ }^{[19]}$, Hadassin ${ }^{[20]}$ and Du Toit ${ }^{[21]}$ reject week-form efficiency but Affleck-Graves and Money ${ }^{[22]}$, Gilbertson and Roux ${ }^{[23]}$ found week-form efficiency for JSE. Given the mixed evidence on efficiency of the JSE, Thompson and Ward $^{[24]}$ showed that there are some share price dependencies, but they are too small to be profitably exploited and concluded that JSE is "operationally efficient". That means, only a small group of investors are able to outperform the market.

Many studies also show the relationship between stock price and exchange rate for different markets. $\mathrm{Yu}^{[25]}$ found a strong long-run stable relationship for Hong Kong, Tokyo, and Singapore. Ajayi, Friedman and Mehdian ${ }^{[26]}$ provided evidence that stock market causes currency markets for the developed countries but no consistent causal relations in the emerging markets. Jefferis and Okeahalam ${ }^{[27]}$ found that real stock prices are positively related to the real exchange rate in South Africa. Nieh and Lee ${ }^{[28]}$ found only short term dynamic relationship for G-7 countries. Fang ${ }^{[29]}$ argued that exchange rates also influence 
stock prices and showed that currency depreciation adversely affected stock returns and increased market volatility over the period of Asian crises: 1997-1999. Bhattacharya and Mukherjee $^{[30]}$ found no significant causal linkage in Indian market. Muhammad and Rasheed ${ }^{[31]}$ worked on four South Asian countries and found no relationship for Pakistan and Indian market either in short-run or in long-run. Stavarek ${ }^{[32]}$ investigates the nature of casual relationship in four EU countries (Austria, France, Germany and U.K), four new EU member countries (Czech Republic, hungry, Poland and Slovakia) and in the USA. The results showed much stronger causality in countries with developed capital and foreign exchange markets than in the new comers.

\section{DATA AND METHODOLOGY}

The data used in this paper is a close daily frequency data on stock indices from the data source of Ecowin, and the exchange rate of the USD/Rand drawn from the South African Reserve Bank. In order to avoid the possible bias, a longer period data is used which reduces the problem of non-trading bias ${ }^{[6]}$ and increases the power of random walk test ${ }^{[33]}$. The sample period included 1,460 daily observations for the total sample period of 2000 to 2004 .

The paper on market efficiency can be divided into two broad categories; one is technical analysis, and another is fundamental analysis. For the technical analysis of cointegration and error correction modelling, it involves three main steps- (a) testing the relevant time series for stationary (unit roots), (b) testing for co-integration, and (c) finally error-correction modelling.

Unit root is one way to see if the time series variable is stationary. The equation of unit root test is,

$$
Y_{t}=\alpha+Y_{t-1}+\mu_{t}
$$

Where $\mu \mathrm{t}$, is the error term with zero mean, constant variance and $\alpha$ is the intercept. Now regression is run based on equation,

$$
\mathrm{Y}_{\mathrm{t}}=\alpha+\rho \mathrm{Y}_{\mathrm{t}-1}+\mu_{\mathrm{t}}
$$

In this regression, it is assumed that, $\rho=1$ means unit root is present and the series are random walk implying non stationarity. If $\mathrm{Y}$ has a unit root, then $\Delta \mathrm{Y}$ will be stationary for this reason.

$$
\Delta \mathrm{Y}_{\mathrm{t}}=\alpha+(\rho-1) \mathrm{Y}_{\mathrm{t}-1}+\mu_{\mathrm{t}}
$$

For simplicity, $\Delta \mathrm{Y}_{\mathrm{t}}=\alpha+\delta \mathrm{Y}_{\mathrm{t}-1}+\mu_{\mathrm{t}}$

Where $\delta=(\rho-1)$ and $\Delta$ is the difference. This might be solved by modifying equation4 by adding lagged difference terms, such as,

$$
\Delta \mathrm{Y}_{\mathrm{t}}=\alpha+\delta \mathrm{Y}_{\mathrm{t}-1}+\alpha \mathrm{i} \sum \Delta \mathrm{Y}_{\mathrm{t}-\mathrm{I}}+\varepsilon_{\mathrm{t}}
$$

Where, $\Delta \mathrm{Y}_{\mathrm{t}-1}=\mathrm{Y}_{\mathrm{t}-1)}-\mathrm{Y}_{(\mathrm{t}-2)}$ etc, $\rho=1$ and $\delta=0$. Then proceed to add enough lagged difference terms until the error term, $\varepsilon_{t}$, becomes serially independent. This modification is 
the augmented Dickey-Fuller test, ADF. Here, Hatemi ${ }^{[34]}$ information Criterion to determine the optimum lag order is used:

$$
\mathrm{HJC}=\ln (|\Pi j|)+\mathrm{j} \times \mathrm{n}^{2}\left(\frac{\ln \mathrm{T}+2 \ln (\ln \mathrm{T})}{2 \mathrm{~T}}\right)^{\prime}
$$

Where $\mathrm{j}=0, \ldots, \rho$. Here $\ln$ signifies the natural logarithm, $|\Pi \mathrm{j}|$ is the determinant of the estimated variance-covariance matrix of the error term for the VAR model for lag order $j, n$ stands for the number of variables, and $t$ is the number of observations used to estimate the VAR model.

The hypothesis is:

$\mathrm{H}_{0}: \rho=1$ one unit root / non stationary.

$\mathrm{H}_{1}: \rho \leq 1$ no unit root / stationary

The drawback of making non-stationary variable stationary is loss of long run information when taking the differences since every difference reverses the time series with one period in time. Co-integration measures the long run co-movement between variables. Thus, a steady growth in error term means there is no co-integration, e.g. if the variables are integrated of order I(1), it does not mean that the error term is integrated in the same order. The error term could be integrated $\mathrm{I}(0)$, implying stationarity, thus a long run relationship between the variables. There are several ways of testing for co-integration but here Engle Granger Co-integration Method is used. This procedure is based on the properties of the OLS regression,

$$
\mathrm{Y}_{\mathrm{t}}=\beta_{0}+\beta_{1} \mathrm{X}_{\mathrm{t}}+\varepsilon_{\mathrm{t}}
$$

where the variables must be estimated Stationarity or non-stationarity can be accomplished with a unit root test using the following equations.

$$
\begin{aligned}
& \varepsilon=\theta_{1} \varepsilon_{\mathrm{t}-1}+\mathrm{V}_{\mathrm{t}} \\
& \Delta \varepsilon_{\mathrm{t}}=\varepsilon_{\mathrm{t}}-\varepsilon_{\mathrm{t}-1}+\mathrm{V}_{\mathrm{t}}=\theta 1 * \varepsilon_{\mathrm{t}-1}+\mathrm{V}_{\mathrm{t}}
\end{aligned}
$$

Where, $\theta 1^{*}=\theta-1$, and $\mathrm{V}_{\mathrm{t}}$ is the residual value. Hence it is perused with estimating an error term residual (with properties of white noise) from two non-stationary $\mathrm{I}(0)$ time series. This linear combination is tested further by implication of the ADF test -whether the cointegration can be estimated depends on the residuals outshine the stationarity test and the linear combination of $\mathrm{I}(0)$ time series becomes stationary at $\mathrm{I}(1)$. The long run equilibrium is estimated upon vector error correction model (VECM) for bivariate time series integrated of the same order and expressed by the regression.

$$
\operatorname{Ln} Y_{t}=\alpha+\Sigma \alpha j \ln X_{t}+u_{t}
$$

Where; $\ln Y_{t}$ is the natural logarithm of the JSE stock index, $\ln X_{t}$ is the natural logarithm of the USD/Rand exchange rate; $\alpha$ is the constant; and $u_{t}$ is the error term.

The null hypothesis of no co-integration, $\mathrm{H}_{0}: \theta 1^{*}=0$

The alternative hypothesis, $\mathrm{H}_{1}: \theta 1 *<0$ 
A question that frequently arises in time series analysis is whether one economic variable can help forecast another economic variable. One way to address this question was proposed by Granger ${ }^{[35]}$ and popularized by Sims ${ }^{[36]}$. Testing causality in the Granger sense, involves using F-test to test whether lagged information on a variable provides any statistically significant information about a variable, $\mathrm{X}$, in the presence of lagged $\mathrm{X}$. If not, then "Y does not Granger cause X".

\section{EMPIRICAL RESULTS}

\section{Unit Root test}

The ADF test is used in order to test for stationarity in both variables, thereby ensuring nonspurious regressions in the empirical results. It is employed to determine the best or optimal lag that will make the data in the series stationary or white noise, thus ready for OLS testing. This choice of the ADF test will be consistent with equation -5. An estimate of the test statistics for the time series is compared with the critical value of the ADF test. This procedure is repeated by taking differences of the time series until stationarity is obtained. Furthermore the optimal lag length for the ADF unit root test is determined based on the chosen information criterion ${ }^{[37]}$ which performs well when the variables are integrated.

\section{$<$ Table $1>$}

Empirical results are based on the 99\% confidence interval critical value of rejection of the unit root hypothesis (Table 1). The lag length is presented in brackets. It is assumed that the hypothesis- $\mathrm{H}_{0}$ to be $\mathrm{I}(1)$ stationary series could not be rejected since the test statistics in absolute terms is lower than the critical value. This also implies that stationarity could not be obtained at $\mathrm{I}(0)$. Thus, the time series must be different at least once to achieve stationarity. The results show insignificant and are not spurious, integrating in the order I(1), hence reliable.

\section{Co-Integration Test}

A continuation of the ADF test is employed in order to test for co-integration using the Engle and Granger method ${ }^{[38]}$. Consistent with theory, non-stationary I(0) time series is employed into an OLS regression in order to estimate an error term/ residual. An ADF test is carried out on these residuals established for OLS regression. It can also be asserted that the residuals tested for unit roots have a linear combination which makes results more reliable. If the variables are non-stationary but a linear combination between them is stationary, then the variables are co-integrated ${ }^{[34]}$. This is shown in results on unit roots for ADF test which tells that the variables are non-stationary. However, a linear combination of the residuals was done and ADF test run on the time series.

\section{$<$ Table 2>}

Empirical result represents rejection of the null hypothesis at $1 \%$ and $5 \%$ significance level when MacKinnon critical value formula is used (Table 2). The t-value of -3.863 in absolute terms exceeds the critical values of -3.571 and -2.923 at $99 \%$ and $95 \%$ confidence intervals respectively. Therefore, the null hypothesis of co-integration cannot be rejected. Thus variables are co-integrated. This shows that it establishes long run equilibrium or a steady state. The result provides that the Johannesburg stock exchange has a long run comovement with exchange rate. The correlation between the stock price index and the exchange rate shows that the JSE is informationally efficient. 


\section{Granger Causality Test}

The result based on the Granger Causality test at 5\% and $1 \%$ level of significance helps to investigate and give meaningful conclusion to whether the JSE is informationally efficient in the Granger sense (Table 3). As co-movement between variables is already found in the market, this section analyzes Granger Causality test in order to investigate a historical comovement between the variables.

\section{$<$ Table 3>}

According to P-values presented in the test, there are no traces of Granger causality. This implies that past values do not affect current observations. The exchange rate (US/Rand) or the stock price index, used as proxies for public information of the JSE, cannot be used by investors to explain or to make abnormal profits since public information is quickly incorporated into stock prices.

\section{CONCLUSIONS}

The objective of this study is to identify the level of EMH in Johannesburg stock exchange with respect to the USD/Rand exchange rate effects on market. Based on the results of the unit root tests, it is found that the time series exhibits a stochastic trend. The bivariate cointegration test also supports this view. In the theoretical review it is highlighted that the concepts of market efficiency and its importance to the South African economy to avoid the mis-pricing of stocks as well as arbitrage opportunities. It is assumed that the model variables are integrated in order I(1), hence reliable. The results provide that the Johannesburg stock exchange has a long run co-movement with exchange rate, and long run equilibrium or steady state. Through co-integration test, this paper gives more insight on the concept of market efficiency and the reliability of the results. In Granger causality test, it has depicted no traces of causality between the variables. So, this study can conclude JSE is semi-strong form efficient. The investors cannot use the exchange rate to forecast or predict stock prices in the Johannesburg stock exchange. So, there is a strong possibility that foreign direct investors and forex market traders cannot influence and make abnormal extra benefit by using exchange rate mechanism from the market

\section{REFERENCES}

1. E Fama, The Behavior of Stock Market Prices, Journal of Business 38, 34-105 (1965)

2. P A Samuelson, Proof that Properly Anticipated Prices Fluctuate Randomly, Industrial Management Review 6, 41-49 (1965)

3. H Working, Price Effects on Future Trading, Food Research Institute Studies 1, 3-33 (1960)

4. V Niederhoffer, MFM Osborne, Market Making and Reversal on the Stock Exchange, Journal of the American Statistical Association 61, 897-916 (1966)

5. JM Poterba, LH Summers, Mean Reversion in Stock Returns: Evidence and Implications, Journal of Financial Economics 22, 27-59 (1988)

6. AW Lo, AC Mackinlay, Stock Market Prices Do Not Follow Random Walks: Evidence from A Simple Specification Test, Review of Financial Studies 1, 41-66 (1988)

7. RJ Shiller, Market Volatility (M.I.T. Press, Mass, 1989)

8. AC Harvey, Time Series Models (Harvester Wheatsheaf, New York 1993)

9. E Balaban, Day of the Week Effects: New Evidence from an Emerging Stock Market, Applied Economics Letters 2(5), 139-43 (1995) 
10. TA Grieb, MG Reyes, Random Walk Tests for Latin American Equity Indexes and Individual Firms, Journal of Financial Research 22(4), 371-383 (1999)

11. H Kawakatsu, MR Morey, An Empirical Examination of Financial Liberalization and the Efficiency of Emerging Market Stock Prices, The Journal of Financial Research 22, 385411 (1999)

12. JL Urrutia, Tests of Random Walk and Market Efficiency for Latin American Emerging Markets, Journal of Financial Research 18, 299-309 (1995)

13. KC Butler, SJ Mailaikah, Efficiency and Inefficiency in Thinly Traded Stock Markets: Kuwait and Saudi Arabia, Journal of Banking and Finance 16, 197-210 (1992)

14. EE Panas, The Behaviour of Athens Stock Prices, Applied Economics 22, No. 12, 1915 1727 (1990)

15. BP Gilbertson, The Performance of South African Mutual Funds (Johannesburg Consolidated Investment Company, Report No. F76/84, Johannesburg 1976)

16. RF Knight, F, JF Affleck-Graves, The Efficient Market Hypothesis and a Change to LIFO: An Empirical Study on the JSE, Investment Analysts Journal 21, 21-33 (1983)

17. ET Knight, C Firer, The Performance of South African Unit Trusts 1977-1986, The South African Journal of Economics 57, No. 1, 52-68 (1989)

18. RF Knight,, JF Affleck-Graves, WD Hamman, The Effect of Inventory Valuation Methods on Share Prices: Some New Evidence for the JSE, Investment Analysts Journal, 26, 45-47 (1985)

19. I Hadassin, An Investigation into the Bahavior of Emerging and Share Prices of South African Listed Companies, Investment Analysts Journal 8, 13-24 (1976)

20. AP Jammine, DM Hawkins, The Behavior of Some Share Indices: A Statistical Analysis, The South African Journal of Economics 42, No. 1, 43-55 (1974)

21. GS Du Toit, Technical Analysis and Market Efficiency on the Johannesburg Stock Exchange (Working Paper for D.Com degree, University of Pretoria, Pretoria 1986)

22. JF Affleck-Graves, AH Money, A Note on the Random Walk Model and South African Share Prices, The South African Journal of Economics 43(3), 382-388 (1975)

23. BP Gilbertson, FJP Roux, Some Further Comments on the Johannesburg Stock Exchange as an Efficient Market, Investment Analysts Journal 11, 21-30 (1978)

24. AR Thompson, MJD Ward, The Johannesburg Stock Exchange as an Efficient Market: A Review, Journal of Studies in Economics and Econometrics 19, No. 3, 33-63 (1995)

25. Q Yu, Stock Price and Exchange Rates: Experience in Leading East Asian Financial Countries: Tokyo, Hong Kong and Singapore, Singapore Economic Review 41, 47-56 (1997)

26. RA Ajayi, J Friedman, SM Mehdian, On the Relationship between Stock Return and Exchange Rate: Test of Granger Causality, Global Finance Journal 9(2), 241-251 (1998)

27. KR Jefferis, CC Okeahalam, The Impact of Economic Fundamentals on Stock Markets in Southern Africa, Development Southern Africa 17(1), 23-51 (2000)

28. CC Nieh, CF Lee, The Dynamic Relationship between Stock Price and Exchange Rate for G-7 Countries, Quarterly Review of Economics and Finance 41(4), 477-490 (2001)

29. W Fang, The Effect of Currency Depreciation on Stock Return: Evidence from five East Asian Economics, Applied Economics Letters, 9(3), 195-199 (2002)

30. B Bhattacharya, J Mukherjee, Causal Relationship between Stock Market and Exchange Rate, Foreign Exchange Reserves and Value of Trade Balance: A Case Study of India (Fifth Annual Conference on Money and Finance in the Indian Economy, January 2003)

31. N Muhammad, A Rashed, Stock Prices and Exchange Rate: Are They Related? Evidence from South Asian Countries (18th Annual general Meeting and Conference of the Pakistan Society of Development Economists, January 2003) 
32. D Stavarek, Linkages between Stock Prices and Exchange Rate in the EU and the United State, Czech Journal of Economics and Finance 55(3-4), 141-161 (2004)

33. JS Taylor, Modelling Financial Time Series (John Wiley and Sons, Chichester 1986)

34. A Hatemi-J, Money Supply and Information Ally Efficiency of the Stock Market in Korea: Evidence from an Alternative Methodology, Journal of Economic Integration 16(3), 427-436 (2002)

35. CWJ Granger, Investigating Causal Relations by Econometric Methods and CrossSpectral Methods, Econometrica 34, 424-438 (1969)

36. C Sims, Money, Income and Causality," American Economic Review 62, 540-552 (1972)

37. A Hatemi-J, A New Method to Choose Optimal Lag Order in Stable and Unstable VAR Models, Applied Economics Letters 1(3), 135-137 (2003)

38. R Engle, C Granger, Co-integration and error correction representation: estimation and testing, Econometrica, 55, 251-276 (1987)

Table 1: Output of Unit Root Test

\begin{tabular}{lccc}
\hline \multirow{2}{*}{ VARIABLES } & $\begin{array}{c}\text { TEST STATISTICS } \\
\text { H0: I(1) vs H1 :I(0) }\end{array}$ & $\begin{array}{c}5 \% \\
\text { CRITICAL } \\
\text { VALUE }\end{array}$ & $\begin{array}{c}\text { CRITICAL } \\
\text { VALUE }\end{array}$ \\
\hline STOCK PRICE INDEX & $-0.68512(1)$ & -2.867 & -3.444 \\
USD/RAND(EXCH) & $-1.4444(1)$ & -2.916 & -3.555 \\
\hline
\end{tabular}

Table 2: Output of Unit Root Test for Residual

\begin{tabular}{lccc}
\hline \multirow{2}{*}{ Variable } & t- values for & critical values at & critical values at \\
& H0: I (1) vs H1:I(0) & $1 \%$ & $5 \%$ \\
\hline \multirow{2}{*}{ Residuals } & -3.863 & -3.571 & -2.923 \\
\hline
\end{tabular}

Table 3: Output of Granger Causality Test

\begin{tabular}{lcc}
\hline Null Hypothesis & F-Statistic & Probability \\
\hline Ex rate does not cause stock prices & 1.18645 & 0.29169 \\
Stock prices does not cause ex rate & 1.08564 & 0.30145 \\
\hline
\end{tabular}

